\title{
Harran Ovası Koşullarında Dereotu (Anethum graveolens L.)'nda Uygun Hasat Zamanının Belirlenmesi
}

\author{
Hüseyin AYHAN ${ }^{1 *}$, Abdulhabip ÖZEL ${ }^{2}$ \\ ${ }^{1}$ GAP Tarımsal Araştırma Enstitüsü Müdürlüğü, ŞANLIURFA \\ [ORCID: http://orcid.org/0000-0002-6971-105X] \\ ${ }^{2}$ Harran Üniversitesi, Ziraat Fakültesi, Tarla Bitkileri Bölümü, ŞANLIURFA \\ [ORCID: http://orcid.org/0000-0002-3605-2596] \\ "Sorumlu yazar: huseyinayhan@hotmail.com
}

Öz

Harran Ovası koşullarında dereotundan yüksek kalite ve verimin alınabileceği uygun hasat zamanlarının belirlenmesi amacıyla yapılan bu çalışma 2014-2015 üretim sezonunda Harran Üniversitesi Ziraat Fakültesi Eyyübiye Yerleşkesi Tarımsal Araştırma ve Uygulama Alanında, tesadüf blokları deneme deseninde 3 tekerrürlü olarak kurulmuştur. Araştırmada dereotunda en uygun hasat zamanını belirlemek için bitkiler $30-40 \mathrm{~cm}$ boylandığından başlamak üzere tohum olgunluğuna kadar 8 farklı zamanda hasat yapılmıştı. Araştırma sonucunda; Taze herba verimi $964.35-4195.00 \mathrm{~kg} \mathrm{da}^{-1}$, kuru herba verimi $239.04-1010.16 \mathrm{~kg} \mathrm{da}^{-1}$, bin tane ağırlığı $1.20-1.55 \mathrm{~g}$, tane verimi $35.68-105.89 \mathrm{~kg} \mathrm{da}^{-1}$, kuru yaprak verimi $56.46-256.45 \mathrm{~kg} \mathrm{da}^{-1}$, uçucu yağ verimleri sırasıyla; Taze herbada $0.20-4.38 \mathrm{I} \mathrm{da}^{-1}$, kuru herbada $0.31-6.38 \mid \mathrm{da}^{-1}$, kuru yaprakta $0.15-2.65 \mid \mathrm{da}^{-1}$ ve tohumda uçucu yağ verimi $0.54-2.03 \mid \mathrm{da}^{-1}$ olarak belirlenmiştir. En yüksek taze herba verimi 2. hasatta (27 Nisan), en yüksek kuru herba verimi 3. hasatta (5 Mayıs), en yüksek uçucu yağ verimi 5. hasatta (5 Haziran), en yüksek tohum verimi ise 7. hasatta (19 Haziran) elde edilmiştir.

Anahtar Kelimeler: Anethum graveolens L., Dereotu, Hasat zamanı, Tohum verimi, Herba verimi

\section{Determination of Suitable Harvesting Time on Dill (Anethum graveolens L.) under the Harran Plain Conditions}

\begin{abstract}
This study was conducted to investigate determination on suitable harvesting times for high quality and yield on dill (Anethum graveolens L.), at Harran University, Faculty of Agriculture, Eyyubiye Campus, Agricultural Research and Application Station, during 2014-2015 growing season under The Harran Plain conditions. The experiment was arranged in randomized blocks design with three replications and different 8 harvesting periods for suitable harvesting. In the research, it were determined that fresh herb yield 964.35-4195.00 kg da ${ }^{-1}$, dry herb yield $239.04-1010.16 \mathrm{~kg} \mathrm{da}^{-1}$, thousand seed weight 1.20$1.55 \mathrm{~g}$, seed yield $35.68-105.89 \mathrm{~kg} \mathrm{da}^{-1}$, dry leaf yield $56.46-256.45 \mathrm{~kg} \mathrm{da}^{-1}$, essential oil yields in fresh herb $0.20-4.38 \mid \mathrm{da}^{-1}$, in dry herb $0.31-6.38 \mathrm{I} \mathrm{da}^{-1}$, in dry leaf $0.15-2.65 \mathrm{I} \mathrm{da}{ }^{-1}$ and in seed $0.54-2.03 \mathrm{I} \mathrm{da}{ }^{-1}$. The highest fresh herb yield were obtained the $2^{\text {th }}$ harvest time (27 April), the highest dry herb yield were obtained the $3^{\text {th }}$ harvest time ( 5 May), the highest essential oil yield were obtained the $5^{\text {th }}$ harvest time (5 June) and the highest seed yield were obtained the $7^{\text {th }}$ harvest time (19 June).
\end{abstract}

Key Words: Anethum graveolens L., Dill, Harvesting time, Seed yield, Herb yield 
Giriş

Dereotu (Anethum graveolens L.), Maydanozgiller [Apiaceae (Şemsiye çiçekliler (Umbelliferae)] familyasından tek yıllık bir baharat bitkisidir. Anavatanı Avrupa'nın güneyi ve Asya'nın batısıdır. Dünyada, uçucu yağ üretimi için birçok Avrupa ülkesinde ve Güney Amerika'da yetiştirilmektedir (Agarwal, 2008). Türkiye'de de yabani olarak bulunduğu gibi, tarımı da yapılmaktadır. Türkiye'de taze sebze olarak dereotu üretimi 2015 yılında 4777 da alanda 4488 ton olarak kaydedilmiştir (Anonim, 2016).

Tıbbi ve aromatik bitkilerin önemini belirleyen ana unsur, içerdiği etken maddelerdir. Bitkilerin içerdiği bu etken maddeler, özellikle uçucu yağlar, başta bitkinin genetik yapısı olmak üzere, iklim, çevresel faktörler, kültürel uygulamalar, bitkinin yetiştirildiği bölge, bitkinin değişik kısımları (morfogenetik varyabilite) (Singh ve Randhawa, 1991), bitkinin gelişme dönemleri (ontogenetik varyabilite) (Özel, 2000) ve gün içerisindeki sıcaklık değişimleri (diurnal varyabilite) (Kaçar ve Özkan, 2005) gibi pek çok faktöre bağlı olarak değişim göstermektedir (Uyanık, 2013).

Uçucu yağ bitkileri ve özellikle herbası ve tohumu ayrı ayrı değerlendirilen dereotu gibi bitkilerde, bitkinin gelişme dönemlerine göre etken madde miktarı ve dağılımının bilinmesi önemlidir. Kaliteli üretim için uygun hasat zamanının bölgelere göre tespit edilmesi gerekmektedir. Bu durum ayrıca, bitkinin gelişim dönemi boyunca etken madde miktar ve dağılımında oluşan değişimler, yeşil sebze olarak da tüketilen dereotunda ayrı önem taşımaktadır. Dereotu bitkisinin Harran Ovası koşullarında yetişebileceği Özel ve ark. (2001) tarafından bildirilmiş ancak, bölgemiz koşullarında yapılan başka bir çalışmaya rastlanılmamıştır. Bilindiği gibi Umbelliferae familyası bitkilerinde, tohum üretiminde karşılaşılan en önemli problem tohum dökme problemidir. Tohum üretiminde, hasadın erken yapılması verim ve kalite kaybına neden olurken, hasatta geç kalınması, tohum dökme dolayısıyla, verim kaybına neden olmaktadır. Bu nedenle, tohum üretimi için de uygun hasat döneminin belirlenmesi gerekmektedir.

Harran Ovası koşullarında kışlık ürün yetiştirme döneminde yetişebilen dereotundan, yüksek kalite ve verimin alınabileceği, uygun hasat zamanlarının belirlenmesi, bölgemizde yapılacak dereotu yetiştiriciliği açısından büyük önem taşımaktadır. Bölgemizde yetişebilen alternatif kışlık bitkilerden biri olan dereotunda, kaliteli herba ve tohum için, en uygun hasat zamanını belirlemek amacıyla, yürütülen bu çalışma; dereotunun içerdiği uçucu yağ miktarının, taze ve kuru herba veriminin, taze ve kuru yaprak veriminin, tohum veriminin, bitkinin hangi gelişme döneminde en fazla olduğunu belirlemek amacıyla yürütülmüştür. Dolayısıyla, dereotu için Harran Ovası koşullarında, herba ve tohum için optimum hasat zamanının belirlenmesi, ileride yapılacak çalışmalara yardımcı olması açısından önem taşımaktadır. 


\section{Materyal ve Metot}

Bu çalışma, 2014-2015 üretim döneminde, Harran Üniversitesi, Eyyübiye Yerleşkesi, Ziraat Fakültesi Tarımsal Araştırma ve Uygulama Alanında, tesadüf blokları deneme deseninde, 3 tekerrürlü olarak yürütülmüştür. Materyal olarak, Şanlıurfa GAP Tarımsal Araştırma Enstitüsü Müdürlüğünden temin edilen, dereotu (Anethum graveolens L.) popülasyona ait tohumlar kullanılmıştır.

Denemenin kurulduğu topraklar alüviyal, ana materyali düz ve düze yakın eğimli derin topraklardır. Tipik kırmızı profilli, killi tekstürlüdür. Tüm profil çok kireçli olup, organik madde içeriği düşük, katyon değişim kapasitesi yüksektir (Dinç ve ark., 1988). Ana materyal alüviyal, derin profilli olup, İkizce serisi toprakları içerisindedir. Tüm profil kil bünyeli olup, kireç ve potasyum kapsamı yüksek, buna karşılık fosfor kapsamı bakımından fakirdir (Anonim, 2006).

Çalışmanın yürütüldüğü dönemde en düşük ortalama sıcaklık $\left(6{ }^{\circ} \mathrm{C}\right)$ Ocak ayında, en yüksek ortalama sıcaklık (26.9 $\left.{ }^{0} \mathrm{C}\right)$ Haziran ayında; en düşük güneşlenme süresi (3.5 saat) Şubat ayında, en yüksek güneşlenme süresi (12.1 saat) Haziran ayında; en düşük nispi nem oranı (\% 35.3) Haziran ayında, en yüksek nispi nem oranı (\% 79.5) Aralık ayında; en düşük yağış miktarı $(0.7 \mathrm{~mm})$ Haziran ayında, en yüksek yağış miktarı (100.8 $\mathrm{mm}$ ) Şubat ayında gerçekleşmiştir. 20142015 ürün yetiştirme döneminde, Şanlıurfa'da toplam $431.6 \mathrm{~mm}$ yağış düşmüştür (Çizelge 1).

Çizelge 1. Şanlıurfa ili aylık ortalama iklim verileri (Anonim, 2015a)

Table 1. Monthly average climate data in Şanlıurfa (Anonymous, 2015a)

\begin{tabular}{lcccc}
\hline $\begin{array}{l}\text { Aylar } \\
\text { Months }\end{array}$ & $\begin{array}{c}\text { Ortalama sıcaklık } \\
\left({ }^{\circ} \mathrm{C}\right) \\
\text { Mean } \\
\text { temperature }\left({ }^{\circ} \mathrm{C}\right)\end{array}$ & $\begin{array}{c}\text { Ortalama } \\
\text { güneşlenme süresi } \\
\text { (saat) } \\
\text { Mean sunshine } \\
\text { duration (hour) }\end{array}$ & $\begin{array}{c}\text { Ortalama nispi } \\
\text { nem (\%) } \\
\text { Mean relative } \\
\text { humidity (\%) }\end{array}$ & $\begin{array}{r}\text { Yağış miktarı (mm) } \\
\text { Precipitation } \\
(\mathrm{mm})\end{array}$ \\
\hline $\begin{array}{l}\text { Kasım-2014 } \\
\text { November-2014 }\end{array}$ & 11.7 & 5.7 & 54.1 & 78.6 \\
$\begin{array}{l}\text { Aralık-2014 } \\
\text { December-2014 }\end{array}$ & 9.6 & 5.2 & 79.5 & 55.4 \\
$\begin{array}{l}\text { Ocak-2015 } \\
\text { January-2015 }\end{array}$ & 6.0 & 3.7 & 68.8 & 82.5 \\
$\begin{array}{l}\text { Şubat-2015 } \\
\text { February-2015 }\end{array}$ & 8.1 & 3.5 & 74.3 & 100.8 \\
$\begin{array}{l}\text { Mart-2015 } \\
\text { March-2015 }\end{array}$ & 11.3 & 5.8 & 58.9 & 79.0 \\
$\begin{array}{l}\text { Nisan-2015 } \\
\begin{array}{l}\text { April-2015 } \\
\text { Mayıs-2015 }\end{array}\end{array}$ & 14.9 & 7.9 & 49.7 & 24.3 \\
$\begin{array}{l}\text { May-2015 } \\
\text { Haziran-2015 }\end{array}$ & 22.4 & 10.4 & 38.0 & 10.3 \\
June-2015 & 26.9 & 12.1 & 35.3 & 0.7 \\
\hline
\end{tabular}


Çizelge 2. Araştırmada uygulanan hasat tarihleri ve bitkinin gelişme dönemleri

Table 2. Harvest date applied in research and plant period of development

\begin{tabular}{|c|c|c|}
\hline $\begin{array}{l}\text { Hasatlar } \\
\text { Harvest }\end{array}$ & $\begin{array}{l}\text { Bitkinin gelişme dönemleri } \\
\text { Plant period of development }\end{array}$ & $\begin{array}{l}\text { Hasat tarih } \\
\text { Harvest date }\end{array}$ \\
\hline $\begin{array}{l}\text { 1. Hasat } \\
1^{\text {th }} \text { Harvest }\end{array}$ & $\begin{array}{l}\text { Bitkiler 30-40 cm boylandığında: Dereotu bitkisi sapa kalkmış ve } \\
\text { dallanmaya yeni başlamıştır. } \\
\text { When plants reached } 30-40 \mathrm{~cm} \text {-length: They formed stems and } \\
\text { started to create branches. }\end{array}$ & $\begin{array}{l}02 \text { Nisan } 2015 \\
\text { April 02, } 2015\end{array}$ \\
\hline $\begin{array}{l}\text { 2. Hasat } \\
2^{\text {th }} \text { Harvest }\end{array}$ & $\begin{array}{l}\text { Tomurcuklanma öncesi: Ana şemsiye daha açılmamıştır. } \\
\text { Prior to budding: Main umbel has not opened yet. }\end{array}$ & $\begin{array}{l}27 \text { Nisan } 2015 \\
\text { April 27, } 2015 \\
\end{array}$ \\
\hline $\begin{array}{l}\text { 3. Hasat } \\
3^{\text {th }} \text { Harvest }\end{array}$ & $\begin{array}{l}\text { Çiçeklenme Öncesi: Ana şemsiye tam tomurcuklanmış ancak } \\
\text { açmamıştır. } \\
\text { Prior to blossoming: Main umbel has totally budded but not } \\
\text { opened yet. }\end{array}$ & $\begin{array}{l}05 \text { Mayıs } 2015 \\
\text { May 05, } 2015\end{array}$ \\
\hline $\begin{array}{l}\text { 4. Hasat } \\
4^{\text {th }} \text { Harvest }\end{array}$ & $\begin{array}{l}\text { Tam çiçeklenme: Ana şemsiye tam çiçeklenmiş yan şemsiyeler } \\
\text { tomurcuklanmıştır. } \\
\text { Complete blossoming: Main umbel has entirely blossommed } \\
\text { and primary umbels has budded. }\end{array}$ & $\begin{array}{l}15 \text { Mayıs } 2015 \\
\text { May 15, } 2015\end{array}$ \\
\hline $\begin{array}{l}\text { 5. Hasat } \\
5^{\text {th }} \text { Harvest }\end{array}$ & $\begin{array}{l}\text { Çiçeklenme sonrası: Ana şemsiyede tohum taslakları görülmeye } \\
\text { başlamış, yan şemsiyeler tam çiçeklenmiştir. } \\
\text { After blooming: Seed coat at the main umbel has started to be } \\
\text { observed and primary umbel totally blossomed. }\end{array}$ & $\begin{array}{l}05 \text { Haziran } 2015 \\
\text { June 05, } 2015\end{array}$ \\
\hline $\begin{array}{l}\text { 6. Hasat } \\
6^{\text {th }} \text { Harvest }\end{array}$ & $\begin{array}{l}\text { Tohum 1: Ana şemsiye tohumları sarımsı kahverengiye } \\
\text { dönmüş, yan şemsiyelerde tohum görülmüştür. } \\
\text { Seed 1: Main umbel seeds has turned into yellowish. }\end{array}$ & $\begin{array}{l}17 \text { Haziran } 2015 \\
\text { June 17, } 2015\end{array}$ \\
\hline $\begin{array}{l}\text { 7. Hasat } \\
7^{\text {th }} \text { Harvest }\end{array}$ & $\begin{array}{l}\text { Tohum 2: Ana şemsiye tohumları tam olgunlaşmış, yan } \\
\text { şemsiyeler sarımsı kahverengiye dönmüştür. } \\
\text { Seed 2: Main umbel seeds have been entirely ripe, primary } \\
\text { umbels have turned into yellowish-brown color. }\end{array}$ & $\begin{array}{l}19 \text { Haziran } 2015 \\
\text { June 19, } 2015\end{array}$ \\
\hline $\begin{array}{l}\text { 8. Hasat } \\
8^{\text {th }} \text { Harvest }\end{array}$ & $\begin{array}{l}\text { Tohum 3: Yan şemsiyelerde tohumlar tam olgunlaşmıştır. } \\
\text { Seed 3: Seeds at the primary umbels have totally been ripe. }\end{array}$ & $\begin{array}{l}30 \text { Haziran } 2015 \\
\text { June } 30,2015\end{array}$ \\
\hline
\end{tabular}

Deneme alanı pullukla derin olarak sürülmüş ve yabancı ot artıkları uzaklaştırılmıştır. Geniş yapraklı yabancı otlara karşı ekim öncesi $200 \mathrm{ml} \mathrm{da}^{-1}$ trifluralin etken maddeli herbisit uygulanmış, daha sonra kültivatörle işlenmiş ve tapan çekilerek ekime hazır hale getirilmiştir. Deneme, ekime hazırlanarak, parselasyonu yapılan deneme alanında, parseller 5 sıradan oluşmuş, parsel boyu $5 \mathrm{~m}$, sıra arası mesafe $30 \mathrm{~cm}$ olacak şekilde kurulmuştur. Her bir parsel alanı $7.5 \mathrm{~m}^{2}$ ( $5 \mathrm{~m} \times 1,5 \mathrm{~m}$ ) olup, deneme 24 parselden oluşmuştur. Ekim $2 \mathrm{~cm}$ derinliğinde, dekara $1.5 \mathrm{~kg}$ tohumluk gelecek şekilde 10 Kasım 2014 tarihinde elle yapılmıştır. Ekimden önce, dekara $5 \mathrm{~kg}$ saf etkili madde gelecek şekilde, 20.20.0 taban gübresi uygulanmıştır. Ekimden sonra, yağmurlama sulama sistemi yöntemiyle, 4 saat sulama yapılmıştır. Denemede, 2 Aralık 2014 tarihinde bitkilerin \% 70'inde çıkış sağlanmıştır. Sapa kalkma döneminde (29 Ocak 2015) dekara 5 kg saf azot olacak şekilde üst gübre uygulanmış ve 1 saat süre ile ek yağmurlama sulama yapılmıştır. Ekimden sonra, yabancı ot durumuna göre, elle yabancı ot mücadelesi yapılmış, yetişme 
süresi içerisinde herhangi bir hastalık ve zararlı görülmemiştir. Dereotu bitkileri çıkıştan itibaren 121 gün sonra sapa kalkmış, 164 gün sonra çiçeklenmiş, ilk hasat 121 . günde, son hasat 210 . günde yapılmıştır.

Ontogenetik varyabiliteyi yani, uçucu yağ oranı bakımından uygun hasat zamanını belirlemek amacıyla kurulan denemede 8 farklı hasat yapılmıştır. Yapılan hasatlara ait tarihler ve bitkinin gelişme dönemleri Çizelge 2'de verilmiştir.

Araştırma, 8 farklı hasat dönemini kapsayacak şekilde planlanmakla beraber; Herba hasadı için ilk 6 dönem $(1,2,3,4,5$ ve 6 . hasatlar) ve tohum hasadı için son 3 dönem $(6,7$ ve 8 . hasatlar) ayrı ayrı değerlendirilmiştir. Araştırmada; bitki boyu, dal sayısı, yaprak oranı ve kuru yaprak verimi, taze ve kuru herba verimleri, şemsiye sayısı, şemsiyede tane sayısı, bin tane ağırlığı ve tane verimi, uçucu yağ oranları ve uçucu yağ verimleri incelenmiştir. Elde edilen ortalama değerler istatistiksel olarak, JMP 7.0 programında varyans analizine tabi tutulmuş ve ortalamalar arasındaki farklılıklar LSD (\% 5) testine göre gruplandırılmıştır.

\section{Araştırma Bulguları ve Tartışma}

\section{Herba Hasadına ilişkin Bulgular}

Harran Ovası koşullarında dereotu (Anethum graveolens L.)'nda uygun hasat zamanının belirlenmesi amacıyla yürütülen çalışmada, herba hasadına ilişkin kaydedilen veriler Çizelge 3'de verilmiştir.
En düşük bitki boyu değeri $42.10 \mathrm{~cm}$ ile 1. hasat döneminde ölçülmüştür. Bu dönemden sonra, bitki boyu olgunlaşmaya doğru giderek artmış ve en yüksek bitki boyu değeri $116.33 \mathrm{~cm}$ ile 6 . hasat döneminden elde edilmiştir. Bitkinin çiçeklenme başlangıcına kadar olan ilk dönemlerinde hızlı bir boylanma gösterdiği, tam çiçeklenme dönemindeki 4. hasattan itibaren bitki boyundaki artış hızının yavaşladığı görülmüştür. Bu durum, bitkinin generatif dönemde olmasından kaynaklanabilir. Genel olarak, vejetasyon süresine bağlı olarak bitki boyu önemli düzeyde artmıştır. Ceylan (1997), dereotu bitkisinin 120 cm'ye kadar boylanabileceğini bildirmiştir. Garrabrants ve Craker (1987)'e göre dereotu bitkisinin ortalama bitki boyu $108.7 \mathrm{~cm}$ 'dir. Randhawa ve ark. (1996), dereotunda ortalama bitki boyunun 117.0-119.3 cm arasında olduğunu bildirmişlerdir. Araştırmadan elde edilen bitki boyu değerleri, araştırmacıların bulgularına benzer bulunmuştur.

En düşük dal sayısı değeri 2.3 adet bitki $^{-1}$ ile 1 . hasat döneminde ölçülmüştür. Dal sayısının olgunlaşmaya doğru arttığı görülmüş, en yüksek dal sayısı değeri 5.9 adet bitki ${ }^{-1}$ ile 6 . hasat döneminden elde edilmiştir. Bitki, sapa kalktığı ve dallanmaya yeni başladığı 1 . hasat döneminden, tomurcuklanma öncesi 2. hasat dönemine kadar hızlı bir dallanma göstermiş, sonraki hasat dönemlerinde dallanmanın yavaşladığı tespit edilmiştir. Bu durum hava sıcaklığının artarak dereotu bitkisini olgunlaştırmasından kaynaklanmış 
olabilir. Randhawa ve ark. (1996)'na göre dereotu bitkisinin dal sayısı 5.36-5.60 adet bitki ${ }^{-1}$ dir. Araştırmadan elde edilen yüksek dal sayısı değerleri, araştırmacıların bulguları ile uyum göstermiştir. Elik (2010), dereotunda dal sayısı değerlerini 3.2-6.3 adet bitki ${ }^{-1}$ olarak bildirmiştir. 1. hasat dışında elde ettiğimiz değerler araştırmacının belirttiği değerler arasında yer almıştır. Özdemir (2005), dereotu dal sayısı değerlerini 3.63-4.57 adet bitki ${ }^{-1}$ olarak belirtmiştir. 2. ve 3 . hasatlardan elde ettiğimiz dal sayısı değerleri araştırmacının belirttiği değerler ile uyum göstermiştir.

En düşük yaprak oranı \% 11.83 ile 6 . hasat döneminde; en yüksek yaprak oranı ise \% 63.82 ile 1 . hasat döneminde ölçülmüştür. Yaprak oranı 1. hasat döneminden sonra önemli oranda azalmıştır. Bu durum, dereotu bitkisinde 1. hasat döneminden sonra bitki boyunun uzaması ve dallanmanın artması ile bitkinin yaşına bağlı olarak sapların kalınlaşıp sertleşmesinden kaynaklanmış olabilir.

En düşük taze herba verimi $964.35 \mathrm{~kg}$ $\mathrm{da}^{-1}$ ile 6 . hasat döneminde, en yüksek taze herba verimi $4195.00 \mathrm{~kg} \mathrm{da}^{-1}$ ile 2 . hasat döneminde gözlenmiştir. Vejetasyon süresi artmasına rağmen, genel olarak artan bitki boyu ve dallanmaya bağlı olarak 2. hasattan sonra taze herba verimi giderek düşmüştür. Bu durum bitkiler arasında olumsuz bir rekabetin oluşmasından, dolayısıyla bitkilerin güneş ışığından ve topraktaki bitki besin elementlerinden daha az faydalanmasının yanında; yağışların giderek düşmesi ve hava sıcaklığının yükselmesi ile bitkilerde oluşan kurumalardan kaynaklanmış olabilir. Nitekim, El-Gengaihi ve Hornok (1978), dereotu bitkisinde en yüksek taze herba veriminin dallanmanın başlangıcında olduğunu ve bundan sonraki dönemlerde düştüğünü tespit etmişlerdir.

En düşük kuru herba verimi $239.04 \mathrm{~kg}$ $\mathrm{da}^{-1}$ ile 1 . hasat döneminde, en yüksek kuru herba verimi $1010.16 \mathrm{~kg} \mathrm{da}^{-1}$ ile 3 . hasat döneminde gözlenmiştir, 2. hasat ile aralarındaki farklılık istatistiki olarak önemsiz olmuştur. Kuru herba verimi 3. hasat döneminde, en yüksek değere ulaşmış ve daha sonraki hasat dönemlerinde giderek azalmıştır. Bu verim azalması, taze herba verimi ile paralellik göstermiştir. Giderek artan bitki boyu ve dallanma ile bitkiler arasında olumsuz rekabet oluşmuştur. Dolayısıyla, bitkiler güneş ışığı ve topraktaki besin elementlerinden yeterince yararlanamamıştır. Ayrıca yağışların giderek düşmesi ve hava sıcaklığının yükselmesi ile bitkilerde oluşan kurumalar da, kuru herba veriminin 3 . hasat döneminden sonra giderek azalmasına neden olmuş olabilir. Darzi (2012), dereotunda kuru herba verimini $1200 \mathrm{~kg} \mathrm{da}^{-1}$ bulmuştur. Çalışmamızdan elde ettiğimiz sonuçlar bu değerin altındadır. Ceylan (1997)'e göre dereotu bitkisinde kuru herba verimi 200-400 kg da ${ }^{-1}$ dır. Araştırmadan elde edilen en düşük kuru herba verimi (1. hasat), araştırmacının belirttiği değerler arasında olup, diğer hasatlatdan alınan değerler daha yüksek olmuştur. ElGengaihi ve Hornok (1978), dereotunda kuru herba verimini $64.5-189.7 \mathrm{~kg} \mathrm{da}^{-1}$ 
olarak tespit etmişlerdir. Araştırmadan elde ettiğimiz değerler, araştırmacıların belirttiği değerlerden yüksek çıkmıştır. Değerler arasındaki bu farklılık genotip, ekolojik koşullar ve yetiştirme tekniği farklılığından kaynaklanmıs olabilir.

En düşük kuru yaprak verimi $56.46 \mathrm{~kg}$ $\mathrm{da}^{-1}$ ile 6 . hasat döneminde, en yüksek kuru yaprak verimi ise $256.45 \mathrm{~kg} \mathrm{da}^{-1}$ ile 4. hasat döneminde ölçülmüş ve bu dönemden sonra kuru yaprak veriminin giderek azaldığı saptanmıştır. Bu durumun bitkinin giderek olgunlaşmasından kaynaklanmış olabileceği düşünülmektedir. Hälvä ve Houpalahti (1987) yaptıkları çalışmada, dereotunda yaprak verimi $100-1780 \mathrm{~kg}$ $\mathrm{da}^{-1}$ arasında bulunmuştur. Araştırmadan elde edilen kuru yaprak verimleri, araştırmacıların buldukları en düşük değere, yakın bulunmuştur.

Çizelge 3. Herba hasadına ilişkin ortalama değerler ve önemlilik grupları

Table 3. Mean values and significance groups for herbage harvest

\begin{tabular}{|c|c|c|c|c|c|c|}
\hline $\begin{array}{l}\text { Hasatlar } \\
\text { Harvest }\end{array}$ & $\begin{array}{l}\text { BB } \\
P H\end{array}$ & $\begin{array}{l}\text { DS } \\
B N\end{array}$ & $\begin{array}{l}Y O \\
L C\end{array}$ & $\begin{array}{l}\text { THV } \\
F H Y\end{array}$ & $\begin{array}{l}\text { KHV } \\
D H Y\end{array}$ & $\begin{array}{l}\text { KYV } \\
D L Y\end{array}$ \\
\hline $\begin{array}{l}\text { 1. Hasat } \\
1^{\text {th }} \text { Harvest }\end{array}$ & $42.10^{\mathrm{e}}$ & $2.3^{C}$ & $63.82^{a}$ & $1986.11^{C}$ & $239.04^{d}$ & $150.19^{b}$ \\
\hline $\begin{array}{l}\text { 2. Hasat } \\
2^{\text {th }} \text { Harvest }\end{array}$ & $76.13^{d}$ & $4.3^{b}$ & $25.53^{C}$ & $4195.00^{a}$ & $985.21^{a}$ & $251.87^{a}$ \\
\hline $\begin{array}{l}\text { 3. Hasat } \\
3^{\text {th }} \text { Harvest }\end{array}$ & $92.00 \mathrm{c}$ & $4.2^{b}$ & $22.22^{\mathrm{C}}$ & $3111.11^{b}$ & $1010.16^{a}$ & $226.09^{a}$ \\
\hline $\begin{array}{l}\text { 4. Hasat } \\
4^{\text {th }} \text { Harvest }\end{array}$ & $104.80^{b}$ & $5.5^{a}$ & $35.01^{b}$ & $3115.00^{b}$ & $735.12^{b}$ & $256.45^{a}$ \\
\hline $\begin{array}{l}\text { 5. Hasat } \\
5^{\text {th }} \text { Harvest }\end{array}$ & $114.0^{\mathrm{ab}}$ & $5.5^{a}$ & $22.14^{\mathrm{C}}$ & $1472.22^{\mathrm{cd}}$ & $600.01^{b c}$ & $133.12^{b}$ \\
\hline $\begin{array}{l}\text { 6. Hasat } \\
6^{\text {th }} \text { Harvest }\end{array}$ & $116.33^{a}$ & $5.9^{a}$ & $11.83^{d}$ & $964.35^{d}$ & $477.18^{C}$ & $56.46^{C}$ \\
\hline $\begin{array}{l}\text { Ortalama } \\
\text { Mean }\end{array}$ & 90.89 & 4.6 & 30.09 & 2473.96 & 674.00 & 178.83 \\
\hline $\begin{array}{l}\text { D.K (\%) } \\
\text { C.V (\%) }\end{array}$ & 6.56 & 9.96 & 10.12 & 14.33 & 11.51 & 18.83 \\
\hline $\begin{array}{l}\text { Önemlilik } \\
\text { Significance }\end{array}$ & $* *$ & $* *$ & $* *$ & $* *$ & $* *$ & $* *$ \\
\hline LSD (0.05) & 10.85 & 0.83 & 5.54 & 645.36 & 141.29 & 61.26 \\
\hline
\end{tabular}

BB: Bitki boyu (cm), DS: Dal sayısı (adet bitki ${ }^{-1}$ ), YO:Yaprak oranı (\%), THV: Taze herba verimi (kg da ${ }^{-1}$ ), KHV: Kuru herba verimi $\left(\mathrm{kg} \mathrm{da}^{-1}\right)$, $\mathrm{KYV}$ :Kuru yaprak verimi $\left(\mathrm{kg} \mathrm{da}{ }^{-1}\right), \mathrm{a}, \mathrm{b}, \mathrm{c}, \mathrm{d}, \mathrm{e}$ : Her sütunda farklı harf taşıyan değerler farklı bulunmuştur $(\mathrm{P}<0.01), \ldots *$ : $\mathrm{P}<0.01$, LSD (0.05): Least Significant Difference

PH: Plant height (cm), BN: Branch number (per plant), LC: Leaf content (\%), FHY:Fresh herb yield (kg da ${ }^{-1}$ ) DHY: Dry

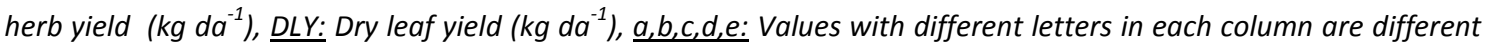
$(P<0.01),{ }^{* *}: P<0.01, \underline{L S D}(0.05)$ : Least Significant Difference 
Çizelge 3. (Devam) Herba hasadına ilişkin ortalama değerler ve önemlilik grupları

Table 3.(Continuation) Mean values and significance groups for herbage harvest

\begin{tabular}{|c|c|c|c|c|c|c|}
\hline $\begin{array}{l}\text { Hasatlar } \\
\text { Harvest }\end{array}$ & $\begin{array}{l}\text { THUYO } \\
\text { EOCFH }\end{array}$ & $\begin{array}{l}\text { KHUYO } \\
\text { EOCDH }\end{array}$ & $\begin{array}{l}\text { KYUYO } \\
\text { EOCDL }\end{array}$ & $\begin{array}{l}\text { THUYV } \\
\text { EOYFH }\end{array}$ & $\begin{array}{l}\text { KHUYV } \\
\text { EOYDH }\end{array}$ & $\begin{array}{l}\text { KYUYV } \\
\text { EOYDL }\end{array}$ \\
\hline $\begin{array}{l}\text { 1. Hasat } \\
1^{\text {th }} \text { Harvest }\end{array}$ & $0.01^{d}$ & $0.13^{d}$ & $0.10^{\mathrm{e}}$ & $0.20^{C}$ & $0.30^{d}$ & $0.15^{\mathrm{C}}$ \\
\hline $\begin{array}{l}\text { 2. Hasat } \\
2^{\text {th }} \text { Harvest }\end{array}$ & $0.02^{d}$ & $0.11^{d}$ & $0.27^{e}$ & $0.77^{C}$ & $1.04^{d}$ & $0.66^{C}$ \\
\hline $\begin{array}{l}\text { 3. Hasat } \\
3^{\text {th }} \text { Harvest }\end{array}$ & $0.08^{C}$ & $0.34^{\mathrm{C}}$ & $0.60^{d}$ & $2.60^{b}$ & $3.53^{C}$ & $1.36^{b}$ \\
\hline $\begin{array}{l}\text { 4. Hasat } \\
4^{\text {th }} \text { Harvest }\end{array}$ & $0.07^{C}$ & $0.38^{\mathrm{C}}$ & $1.03^{C}$ & $2.09^{b}$ & $2.74^{C}$ & $2.65^{a}$ \\
\hline $\begin{array}{l}\text { 5. Hasat } \\
5^{\text {th }} \text { Harvest }\end{array}$ & $0.30^{a}$ & $1.15^{a}$ & $1.80^{\mathrm{a}}$ & $4.38^{a}$ & $6.89^{a}$ & $2.38^{a}$ \\
\hline $\begin{array}{l}\text { 6. Hasat } \\
6^{\text {th }} \text { Harvest }\end{array}$ & $0.23^{b}$ & $0.96^{b}$ & $1.28^{b}$ & $2.23^{b}$ & $4.58^{b}$ & $0.72^{C}$ \\
\hline $\begin{array}{l}\text { Ortalama } \\
\text { Mean } \\
\end{array}$ & 0.12 & 0.51 & 0.85 & 2.04 & 3.18 & 1.32 \\
\hline $\begin{array}{l}\text { D.K (\%) } \\
\text { C.V (\%) } \\
\end{array}$ & 16.38 & 9.00 & 13.78 & 21.77 & 18.07 & 25.25 \\
\hline $\begin{array}{l}\text { Önemlilik } \\
\text { Significance }\end{array}$ & $* *$ & $* *$ & $* *$ & $* *$ & $* *$ & $* *$ \\
\hline LSD (0.05) & 0.03 & 0.08 & 0.21 & 0.80 & 1.04 & 0.60 \\
\hline
\end{tabular}

THUYO: Taze herbada uçucu yağ oranı (\%), KHUYO: Kuru herbada uçucu yağ oranı (\%), KYUYO: Kuru yaprakta uçucu yağ oranı (\%), THUYV: Taze herbada uçucu yağ verimi $\left(I \mathrm{da}^{-1}\right)$, KHUYV: Kuru herbada uucu yağ verimii $\left(I \mathrm{da}^{-1}\right)$, KYUYV: Kuru yaprakta uçucu yağ verimi $\left(I d^{-1}\right), \underline{a, b, c, d, e: ~ H e r ~ s u ̈ t u n d a ~ f a r k l ı ~ h a r f ~ t a s ̧ ı y a n ~ d e g ̆ e r l e r ~ f a r k l ı ~ b u l u n m u s ̧ t u r ~}$ $(\mathrm{P}<0.01)$, **: $\mathrm{P}<0.01, \underline{\mathrm{LSD}}(0.05)$ : Least Significant Difference

EOCFH: Essential oil contents in fresh herb (\%), EOCDH: Essential oil contents in dry herb (\%), EOCDL: Essential oil contents in dry leaf (\%), EOYFH: Essential oil yields in fresh herb (I da $\left.{ }^{-1}\right)$, EOYDH: Essential oil yields in dry herb (I da $\left.{ }^{-1}\right)$,

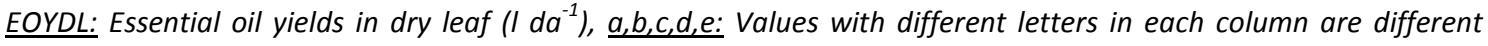
$(P<0.01)$

En düşük taze herba uçucu yağ oranı $\% 0.01$ ile 1. hasat döneminde, en yüksek taze herba uçucu yağ oranı ise \% 0.30 ile 5. hasat döneminde ölçülmüştür. Çiçeklenme sonrası dönemlerde taze herba uçucu yağ oranında önemli artış tespit edilmiştir. Bu artış herbaya dahil olan generatif organların artışından kaynaklanabilir. Nitekim Özdemir (2005), yaptığı araştırmada en yüksek uçucu yağ oranının çiçeklenme sonrası dönemden alındığını bildirmiştir.

En düşük kuru herba uçucu yağ oranı $\% 0.11$ ile 2. hasat döneminde, en yüksek kuru herba uçucu yağ oranı ise \% 1.15 ile 5. hasat döneminde ölçülmüştür. Çiçeklenme sonrası dönemlerde kuru herba uçucu yağ oranında önemli artış tespit edilmiştir. $\mathrm{Bu}$ artış sıcaklıkların yükselmesine bağlanabilir. Ceylan (1997), dereotu bitkisinde drog herbada uçucu yağ oranının \% 0.53 olduğunu belirtmiştir. Araştırmadan elde edilen 1, 2,3 ve 4 . hasat dönemlerindeki kuru herba uçu yağ oranları araştırmacının belirttiği değerden düşük, sonraki hasat dönemlerinde ise yüksek çıkmıştır. Anonim (2015b)'de belirtildiği üzere 
dereotunda kuru herbada uçucu yağ oranları \% 0.3 ile \% 1.5 arasında değişim göstermiştir. Araştırmadan elde edilen 3 , 4,5 ve 6 . hasatlardaki uçucu yağ oranları bu değerler arasında yer almıştır.

En düşük kuru yaprak uçucu yağ oranı $\% 0.10$ ile 1. hasat döneminde, en yüksek kuru yaprak uçucu yağ oranı ise \% 1.80 ile 5. hasat döneminde gözlenmiştir. Çiçeklenme sonrası dönemlerde kuru yaprak uçucu yağ oranında önemli artış tespit edilmiştir. Nitekim, Özdemir (2005) yaptığı araştırmada en yüksek uçucu yağ oranının çiçeklenme sonrası dönemden alındığını bildirmiştir. Hälvä ve ark. (1993), yaptıkları çalışmada sıcaklıkların artması ile dereotunda uçucu yağ oranının arttığını bildirmişlerdir. Ayrıca, Said-Al Ahl ve ark. (2015), yaptıkları araştırmada uçucu yağ oranının vejetatif dönemden, çiçeklenme dönemine doğru artış gösterdiğini bildirmişlerdir.

En düşük taze herba uçucu yağ verimi $0.20 । \mathrm{da}^{-1}$ ile 1 . hasat döneminden, en yüksek taze herba uçucu yağ verimi ise $4.38 \mathrm{I} \mathrm{da}^{-1}$ ile 5 . hasat döneminden elde edilmiştir. Çiçeklenme sonrası dönemlerde taze herba uçucu yağ veriminde görülen artışın, taze herba uçucu yağ oranına paralel olarak arttığı, bu artışta sıcaklık yükselmelerinin etkili olduğu söylenebilir.

En düşük kuru herba uçucu yağ verimi $0.31 \mathrm{I} \mathrm{da}^{-1}$ ile 1 . hasat döneminde, en yüksek kuru herba uçucu yağ verimi ise $6.89 \mathrm{I} \mathrm{da}^{-1}$ ile 5 . hasat döneminde saptanmıştır. Çiçeklenme sonrası dönemlerde kuru herba uçucu yağ veriminde, kuru herba uçucu yağ oranına paralel artış tespit edilmiştir. Bu artış sıcaklıkların yükselmesine bağlanabilir.

En düşük kuru yaprak uçucu yağ verimi $0.15 \mathrm{I} \mathrm{da}^{-1}$ ile 1 . hasat döneminde, en yüksek kuru yaprak uçucu yağ verimi ise $2.65 \mathrm{I} \mathrm{da}^{-1}$ ile 4 . hasat döneminde ölçülmüştür. Tam çiçeklenme döneminde kuru yaprak uçucu yağ veriminde önemli bir artış tespit edilmiştir. Fakat bu artış kuru yaprak uçucu yağ oranından sapma göstermiştir. Bu durum, en yüksek yaprak veriminin 4 . hasattan elde edilmesinden kaynaklanmıştır.

\section{Tohum Hasadına Iilişkin Bulgular}

Harran Ovası Koşullarında Dereotu (Anethum graveolens L.)'nda Uygun Hasat Zamanının Belirlenmesi amacıyla yürütülen çalışmada tohum hasadına ilişkin gözlenen veriler Çizelge $4^{\prime}$ de verilmiştir

Generatif dönemde farklı hasat zamanlarına ait ortalama bitki boyları; 6 . hasat ve 7. hasat dönemlerinde sırasıyla 116.33 ve $116.66 \mathrm{~cm}$; 8 . hasat döneminde ise $117.65 \mathrm{~cm}$ olarak ölçülmüştür ve 3 farklı hasat döneminde bitki boyunun artı neredeyse değişmediği ve boylanmanın durduğu tespit edilmiştir. Bu durum, generatif döneme geçtikten sonra bitkide boy uzamasının durmasından kaynaklanabilir. Ceylan (1997), dereotu bitkisinin 120 cm'ye kadar boylanabileceğini bildirmiştir. Garrabrants ve Craker (1987)'e göre dereotu bitkisinin ortalama bitki boyu 108.7 cm'dir. Randhawa ve ark. (1996), dereotunda ortalama bitki boyunun 117.0-119.3 cm arasında olduğunu bildirmişlerdir. Araştırmadan 
elde edilen bitki boyu değerleri, araştırmacıların bulgularına benzer bulunmuştur.

Ortalama dal sayıları, 6 . hasat döneminde 5.9 adet bitki ${ }^{-1} ; 7$ ve 8 . hasat dönemlerinde ise 6.1 adet bitki ${ }^{-1}$ olarak ölçülmüştür ve 3 farklı hasat döneminde dereotu bitkisinde dal sayısının artık neredeyse değişmediği ve dallanmanın durduğu tespit edilmiştir. Bu durum, yağışların azalması ve hava sıcaklığının artarak dereotu bitkisini olgunlaştırmasından kaynaklanabilir. Randhawa ve ark. (1996)'na göre dereotunda dal sayısı 5.36-5.60 adet bitki ${ }^{-1}$ dir. Elik (2010), dereotunda dal sayısı değerlerini 3.2-6.3 adet bitki ${ }^{-1}$ olarak bildirmiştir. Araştırmadan elde edilen yüksek dal sayısı değerleri, araştırmacıların bulguları ile uyum göstermiştir. Özdemir (2005), dereotunda dal sayısı değerlerini 3.634.57 adet bitki $^{-1}$ olarak belirtmiştir. Son 3 hasattan elde etiğimiz dal sayısı değerleri araştırmacının belirttiği değerlerden yüksek ölçülmüştür.

Ortalama şemsiye sayıları; 6. hasat döneminde 5.1 adet bitki ${ }^{-1}$ ile en düşük; 8. hasat döneminde ise 5.8 adet bitki ${ }^{-1}$ ile en yüksek olarak ölçülmüş ve tane tutan şemsiye sayısı giderek artmıştır. Bu durum bitkinin giderek olgunlaşmasından kaynaklanmıştır. Randhawa ve ark. (1987), şemsiye sayısını bitki başına 12.10-17.20 adet bitki ${ }^{-1}$ olarak, Randhawa ve ark. (1996), bitki başına 26.30-27.00 adet bitki ${ }^{-1}$ olarak bildirmişlerdir. Bulgularımız araştırmacıların değerlerinden çok düşük olmuştur. Özdemir (2005), dereotunda şemsiye sayısını $3.20-4.20$ adet bitki ${ }^{-1}$ olarak bulmuştur. Bulgularımız araştırıcının değerlerinden yüksek olmakla beraber yakınlık göstermiştir.

Şemsiye başına ortalama tane sayıları; 8. hasatta 898.33 adet şemsiye ${ }^{-1}$ ile en düşük; 7. hasat döneminde ise 1461.33 adet şemsiye ${ }^{-1}$ ile en yüksek olarak ölçülmüştür. Bitkinin tam olgunlaştığı 8 . hasat döneminde ise önemli bir düşüş göstermiştir. $\mathrm{Bu}$ durum, hasadın gecikmesinden dolayı şemsiyelerden tohum dökülmesinden kaynaklanmıştır. Özdemir (2005), şemsiyede tane sayısını 904-1752 adet şemsiye ${ }^{-1}$ olarak bulmuştur. Araştırmadan elde edilen yüksek değerler, araştırıcının bulguları arasında yer almıştır.

Ortalama bin tane ağırlığı değerleri; 6 . hasat döneminde $1.20 \mathrm{~g}$ ile en düşük; 8 . hasat döneminde ise $1.55 \mathrm{~g}$ ile en yüksek olarak ölçülmüştür. Bin tane ağırlığı değerleri bitkinin olgunlaşmasıyla birlikte giderek artış göstermiştir. Ceylan (1997), dereotunda bin tane ağırlığını 0.98-2.07 g olarak bildirmiştir. Bazı araştırıcılar ise dereotunda bin tane ağırlığının 1.19 ile $1.70 \mathrm{~g}$ arasında değiştiğini tesbit etmişlerdir (Wonder ve Bouwmesster, 1998; Bailer ve ark. 2002; Hashemzadeh ve ark., 2013). Araştırmadan elde edilen bin tane ağırlıkları bu değerler arasında yer almıştır.

Ortalama tane verimleri; 8 . hasat döneminde $35.68 \mathrm{~kg} \mathrm{da}^{-1}$ ile en düşük; 7 . hasat döneminde ise $105.89 \mathrm{~kg} \mathrm{da}^{-1}$ ile en yüksek olarak ölçülmüştür. Tane verimi, şemsiyede tane sayısı ile paralellik göstermiş olup, 7. hasat döneminde en yüksek değere ulaşmış, bitkinin tam 
olgunlaştığı 8. hasat döneminde ise önemli bir düşüş göstermiştir. Bu durum, hasadın gecikmesinden dolayı şemsiyelerden tohum dökülmesinden kaynaklanmıştır. Dereotunda tane verimi değişken olup, bu değer 27.9 ile $150 \mathrm{~kg}$ $\mathrm{da}^{-1}$ arasında değişmektedir (Randhawa ve ark. 1987; Ceylan, 1997; Randhawa ve Singh, 1989; Dachler ve Pelzmann, 1999). Araştırmadan elde edilen en yüksek değer, araştırıcıların belirttiği değere yakın bulunmuştur.

Tohumda ortalama uçucu yağ oranları; 8. hasat döneminde \% 1.52 ile en düşük; 6 . hasat döneminde $\% 2.20$ ile en yüksek olarak ölçülmüştür. Bitkinin tohumları olgunlaştıkça uçucu yağ oranının düştüğü gözlenmiştir. Nitekim bazı araştırıcılar da benzer şekilde dereotunda uçucu yağ oranının tohum olgunlaştırma başlangıcında en yüksek olduğunu bildirmişlerdir (Shokati ve Ghassemi-Golezan, 2013; Kerimzadeh ve ark. 2015). Randhawa ve ark. (1987) dereotu tohumunda uçucu yağ oranının \% 1.68-2.72; Badoc ve Lamarti (1991), \% 1.75-4.80 olduğunu, Muggeridge ve Clay (2002) en düşük \% 1 olması gerektiğini ve Santos ve ark. (2002) ise, tohumdaki uçucu yağ oranının \% 2 civarında olduğunu bildirmişlerdir. Çalışmamızdan elde edilen değerler, araştırıcıların belirttiği oranlara yakın bulunmuştur.

Çizelge 4. Tohum hasadına ilişkin ortalama değerler ve önemlilik grupları

Table 4. Mean values and significance groups for seed harvest

\begin{tabular}{|c|c|c|c|c|c|c|c|c|}
\hline $\begin{array}{l}\text { Hasatlar } \\
\text { Harvest }\end{array}$ & $\begin{array}{l}\mathrm{BB} \\
\mathrm{PH}\end{array}$ & $\begin{array}{l}\text { DS } \\
B N\end{array}$ & $\begin{array}{l}\text { ŞS } \\
\text { UN }\end{array}$ & $\begin{array}{l}\text { ŞTS } \\
\text { SNU }\end{array}$ & $\begin{array}{l}\text { BTA } \\
\text { TSW }\end{array}$ & $\begin{array}{l}\text { TV } \\
\text { SW }\end{array}$ & $\begin{array}{l}\text { TUYO } \\
\text { EOCS }\end{array}$ & $\begin{array}{l}\text { TUYV } \\
\text { EOYS }\end{array}$ \\
\hline $\begin{array}{l}\text { 6. Hasat } \\
6^{\text {th }} \text { Harvest }\end{array}$ & 116.33 & 5.9 & $5.1^{b}$ & $1329.00^{a}$ & $1.20^{C}$ & $86.03^{b}$ & $2.20^{a}$ & $1.88^{a}$ \\
\hline $\begin{array}{l}\text { 7. Hasat } \\
7^{\text {th }} \text { Harvest }\end{array}$ & 116.66 & 6.1 & $5.2^{b}$ & $1461.33^{a}$ & $1.40^{b}$ & $105.89^{a}$ & $1.91^{a}$ & $2.03^{a}$ \\
\hline $\begin{array}{l}\text { 8. Hasat } \\
8^{\text {th }} \text { Harvest }\end{array}$ & 117.65 & 6.1 & $5.8^{a}$ & $898.33^{b}$ & $1.55^{\mathrm{a}}$ & $35.68^{C}$ & $1.52^{b}$ & $0.54^{b}$ \\
\hline $\begin{array}{l}\text { Ortalama } \\
\text { Mean }\end{array}$ & 116.83 & 6.0 & 5.4 & 1229.55 & 1.38 & 75.86 & 1.88 & 1.48 \\
\hline $\begin{array}{l}\text { D.K (\%) } \\
\text { C.V (\%) }\end{array}$ & 4 & 3.46 & 4.35 & 10.48 & 0.78 & 10.82 & 8.73 & 15.95 \\
\hline $\begin{array}{l}\text { Önemlilik } \\
\text { Significance }\end{array}$ & $\begin{array}{l}\text { Ö.D } \\
N S\end{array}$ & $\begin{array}{l}\text { Ö.D } \\
N S\end{array}$ & $*$ & $*$ & $* *$ & $* *$ & $*$ & $*$ \\
\hline LSD (0.05) & $\begin{array}{l}\text { Ö.D } \\
N S\end{array}$ & $\begin{array}{l}\text { Ö.D } \\
N S\end{array}$ & 0.52 & 292.35 & 0.02 & 18.61 & 0.37 & 0.53 \\
\hline
\end{tabular}

BB: Bitki boyu (cm), DS: Dal sayısı (adet bitki ${ }^{-1}$ ), ŞS: Şemsiye Sayısı (adet bitki ${ }^{-1}$ ), șTS: Şemsiyede Tane Sayısı (adet şemsiye ${ }^{-1}$ ), BTA: Bin Tane Ağırlığı (g), TV: Tane Verimi (kg), TUYO: Tohumda Uçucu Yağ Oranı (\%), TUYV: Tohumda Uçucu Yağ Verimi (It da $\left.{ }^{-1}\right)$ a,b,c,d,e: Her sütunda farklı harf taşıyan değerler farklı bulunmuştur $(\mathrm{P}<0.01),{ }^{* *}$ : $\mathrm{P}<0.01$, *: P $\leq$ 0.05, Ö.D: Önemli Değil, LSD (0.05): Least Significant Difference

PH: Plant height (cm), BN: Branch number (per plant), UN: Umbel number (per plant), SNU: Seed number per umbel (per umbel), TSW: Thousand seed weight (g), SW: Seed weight ( $\mathrm{kg})$, EOCS: Essential oil content in seed (\%), EOYS: Essential oil yield in seed ( $\left.\left.d^{-1}\right)^{-1}\right)$ ), $a, b, c, d, e:$ Values with different letters in each column are different $(P<0.01)$ 
Tohumda ortalama uçucu yağ verimleri; 8. hasat döneminde $0.54 \mathrm{I} \mathrm{da}^{-1}$ ile en düşük; 7. hasat döneminde ise 2.03 I da ${ }^{-1}$ ile en yüksek olarak ölçülmüştür. Tohumlar olgunlaştıkça uçucu yağ oranının düştüğü saptanmış; ancak tohumdaki uçucu yağ verimi, tohum verimine bağlı olarak en yüksek 7 . hasat döneminden elde edilmiştir. Çalışmadan elde ettiğimiz sonuçlar, geç ekimlerin uçucu yağ oranını azalttığını bildiren Bowes ve ark. (2004)'nın bulgularıyla benzerlik göstermiştir.

\section{Sonuç ve Öneriler}

Dereotu bitkisinde taze herba kullanımları için hasadın, verimin en yüksek (4195 kg da-1) olduğu 2. hasat döneminde (27 Nisan), ana şemsiyenin henüz açılmadığı tomurcuklanma öncesi dönemde yapılması gerektiği saptanmıştır. Bundan sonraki dönemlerde yağışların giderek azalması ve hava sıcaklığının yükselmesi ile birlikte, bitkide oluşan kurumaların yanısıra, bitkinin generatif döneme geçmesi, taze herba veriminde düşüşe neden olmuştur. Dereotu bitkisinin sebze olarak kullanımında, tarlayı erken boşaltması ve bir sonraki ürün için geniş zaman bırakması avantaj sağlamıştır.

Yüksek uçucu yağ verimi bakımından hasadın, 5. hasat döneminde (5 Haziran), yani tam çiçeklenme sonrası dönemden hemen sonra yapılması gerektiği saptanmıştır.

Yüksek tohum verimi bakımından hasadın, tohum veriminin en yüksek (105.89 kg da ${ }^{-1}$ ) olduğu 7. hasat döneminde (19 Haziran), yani ana şemsiye tohumlarının tam olgunlaştığı, yan şemsiyelerin sarımsı kahverengiye döndüğü dönemde yapılması gerektiği saptanmıştır. Bu dönemde tohumdaki uçucu yağ verimi de en yüksek değere (2.03 I da $\left.{ }^{-1}\right)$ ulaşmıştır.

\section{Ekler}

$\mathrm{Bu}$ makale, 27/05/2016 tarihinde, HRÜ Fen bilimleri Enstitüsünce kabul edilen ve Harran Üniversitesi araştırma fonu tarafindan desteklenen (Proje No: 15077) Yüksek Lisans Tezinden çıkarılmıştır.

\section{Kaynaklar}

Agarwal, A. A., 2008. Chemical Composition of Major Essential Oil of India. Published by Swaraj Herbal Plants Ltd. Barabanki, India. p: 281.

Anonim, 2006. Köy Hizmetleri Genel Müdürlüğü Şanlıurfa Araştırma Enstitüsü Müdürlüğü, Şanlıurfa.

Anonim, 2015a. Şanlıurfa Meteoroloji Bölge Müdürlüğü. Şanlıurfa illi Aylık Ortalama iklim Verileri.

Anonim, 2015b.

http://www.harvestfields.netfirms.com/h erbs/spice/dill.htm. Kuru Herbada Uçucu Yağ Oranları.

Anonim, 2016. http://www.tuik.gov.tr. Türkiye'de Yeşil Sebze Olarak Dereotu Üretimi.

Badoc, A., Lamarti, A., 1991. A Chemotaxonomic Evaluation of Anethum graveolens L. (Dill) of Various Origins. J. Essential Oil Resarch, 3, 269- 278

Bailer, J., Aichinger, T., Hacki, G., Hueber, K., Dachler, M., 2002. Essential Oil Content and Composition in Commercially Available Dill Cultivars in Comparison to Caraway. Industrial Crops and Products, 14.3: 229-239.

Bowes, K. M., Zheljazkov, V. D., Caldwell, C. D., Pincock, J. A., Roberts, J. C., 2004. Influence of Seeding Date and Harvest 
Stage on Yields and Essential Oil Composition of Three Cultivars of Dill (Anethum graveolens L.) Grown in Nova Scotia. Canadian Journal of Plant Science, 84(4), 1155-1160.

Ceylan, A., 1997. Tıbbi Bitkiler II (Uçucu Yağ Bitkileri). Ege Üniversitesi Ziraat Fakültesi, Yayın No: 481, s.57, 161-175.

Dachler, M., Pelzmann, H., 1999. Arznei-und Gewurzpflanzen, 2nd ed. O-sterreichischer Agrarverlag, Klosterneuburg (Austria) 156 pp.

Darzi, M., 2012. Influence of Organic Fertilizer and Biostimulant on The Growth and Biomass of Dill (Anethum graveolens L.). International Journal of Agriculture and Crop Sciences.

Dinç, U., Şenol, S., Sayın, M., Kapur, S., Güzel, N., 1988. Güneydoğu Anadolu Bölgesi Toprakları (GAT) I. Harran Ovası, TÜBiTAK, Tarım Ormancılık Araştırma Grubu, Güdümlü Araştırma Projesi Kesin Sonuç Raporu, TAOG, 534, Adana.

El-Gengaihi, S. E., Hornok, L., 1978. The Effect of Plant Age on Content And Composition of Dill Essential Oil Anethum graveolens L. Acta Horticulturae, Spices and Medicinal Plants, p: 213- 218.

Elik, H., 2010. Diyarbakır Ekolojik Koşullarında Farklı Ekim Zamanlarının Dereotu (Anethum graveolens L.)'nda Bazı Agronomik ve Teknolojik Özellikler Üzerine Etkisi. Yüksek Lisans Tezi, Çukurova Üniversitesi, Fen Bilimleri Enstitüsü.

Garrabrants, N. L., Craker, L. E., 1987. Optimizing Field Production of Dill. Acta Horticulturae, Medicinal and Aromatic Plants, 208:69-72.

Hälvä, S., Houpalahti, R., 1987. The Effect of Variety and Location on The Production and Aroma of Dill Herb. Acta Horticulturae, Medicinal and Aromatic Plants, 208. P: 45- 49.

Hälvä, S., Craker, J. E., Simon, D. J., 1993. Growth and Essential Oil in Dill, Anethum graveolens L., in Response to Temperature and Photoperiod. Journal of Herbs, Spices \& Medicinal Plants. P: 47-56

Hashemzadeh, F., Mirshekari, B., Khoei, F., Yarnia, M., Tarinejad, A., 2013. Effect of Bio and Chemical Fertilizers on Seed Yield and Its Components of Dill (Anethum graveolens L.). Journal of Medicinal Plants, Vol. 7(3), pp. 111117.

Kaçar, O., Özkan, N., 2005. Çeşitli İklim Faktörlerinin, Farklı Gelişme Dönemlerinin ve Gün İçerisindeki Farklı Toplama Saatlerinin Sarı Kantaron (Hypericum perforatum L.)'da Hiperisin Oranı Üzerine Etkisinin Belirlenmesi. Ege Üniv. Ziraat Fak. Dergisi, 42(2):23-34.

Karimzadeh, P., Salmasi, S., Kalvanagh, J., Janmohammadi H., 2015. Essential Oil Production of Dill Affected by Different Intercropping Patterns With Berseem Clover and Harvesting Times. International Journal of Biosciences, Vol. 6, No. 3, p. 1-6.

Muggeridge, M., Clay M., 2002. Quailty Specifications for Herbs and Spices. Handbook of Herbs and Spices, European Spice Association.

Özdemir, Z., 2005. Dereotu (Anethum graveolens L.)'nda Bitki ve Tohum Verimi İçin Uygun Hasat Zamanlarının Belirlenmesi. Yüksek Lisans Tezi, Çukurova Üniversitesi, Fen Bilimleri Enstitüsü.

Özel, A., 2000. Harran Ovası Koşullarında Kıvırcık Nane (Mentha spicata L.)'de Farklı Biçim Zamanlarının Drog Verimi ve Bazı Kalite Kriterlerine Etkisi. HR.Ü. Ziraat Fakültesi Dergisi, 4(1-2), 45-56.

Özel, A., Demirbilek, T., Çopur, O., 2001. Determination of Yield and Agronomic Characters of Some Annual Spice Plants Under The Harran Plain Conditions. Workshop on Agricultural and Quality, Aspects of Medicinal and Aromatic Plants, 151-158. Adana-TURKEY.

Randhawa, G. S., Singh, A., Mahey, R. K., 1987. Optimising Agronomic Requirements For Seed Yield and Quality of Dill (Anethum graveolens L.) Oil. Acta Horticulturae 208, Medicinal and Aromatic Plants, P: 61- 68.

Randhawa, G. S., Singh, A., 1989. Effect of Agronomic Practices on Growth, Yield and Nutrient Uptake of Dill (Anethum graveolens L.), Horticultural Abstracts, Vol. 59, No:9, 882.

Randhawa, G. S., Gill, B. S., Saini, S. S., Singh, J., 1996. Effect of Plant Spacings and Nitrogen Levels on The Seed Yield of Dill Seed (Anethum graveolens L.), Proceedings Int. Symp. Medicinal an Aromatic Plants, Acta Hort. 426, p:623628.

Said, A. A., Atef, M. Z., Sarhan, A. D., El-Shahat, A. Z., Mohamed, S. A., Nabila, Y. N., 2015. Volatile Oil Composition of Anethum graveolens L. Affected by Harvest Stage. International Journal of Plant Science and Ecology, Vol. 1, No. 3, pp. 93-97. 
Santos, P. A. G., Figueiredo, A. C., Lourenco, P. M. L., Barosso, J. G., Pedro, L. G., Oliveira, M. M., Schripsema, J., 2002. Hairy Cut Cultures of Anethum graveolens L. (Dill) Establishment, Growth, Time-Course Study of Their Essential Oil and Its Comparsion With Parent Plant Oils, Horticultural Abstracts, Vol. 72, No: 12, 1636.

Shokati, K., Ghassemi, G., 2013. Effects of Fenugreek And Dill Different Intercropping Patterns And Harvesting Times On Essential Oil of Dill. Cercetari Agronomice in Moldova, Vol. XLVI, No. 3 (155).
Singh, A., Randhawa G. S., 1991. Effect of Cultural-Practices on Periodic Plant Height and Seed Yield of Dill (Anethum graveolens L.). Indian Journal of Agronomy, 36 (4): 574-577.

Uyanık, M., 2013. Oğulotu (Melissa officinalis L.)'nda Ontogenetik, Morfogenetik ve Diurnal Varyabilitenin Ankara Koşullarında Belirlenmesi. Yüksek Lisans Tezi, Ankara Üniversitesi, Fen Bilimleri Enstitüsü.

Wander, J., Bauwmeester, H., 1998. Effects of Nitrogen Fertilization on Dill (Anethum graveolens L.) Seed and Carvone Production. Industrial Crops and Products, 7, 211-216. 